\title{
The biofiltration process by the bivalve $D$. polymorpha for the removal of some pharmaceuticals and drugs of abuse from civil wastewaters
}

\author{
Andrea Binelli ${ }^{a}, *$, Stefano Magni ${ }^{a}$, Carlo Soave $^{a}$, Francesca Marazzi $^{\mathrm{b}}$, Ettore Zuccato ${ }^{\mathrm{c}}$, \\ Sara Castiglioni ${ }^{c}$, Marco Parolini $^{a}$, Valeria Mezzanotte ${ }^{b}$ \\ a Department of Biosciences, University of Milan, Via Celoria 26, 20133 Milan, Italy \\ ${ }^{\mathrm{b}}$ Department of Environmental and Territory Science, University of Milan-Bicocca, Piazza della Scienza 1, 20126 Milan, Italy

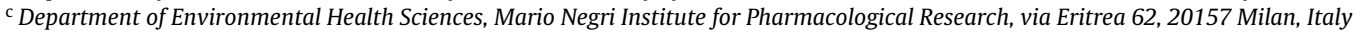

\section{A R T I C L E I N F O}

\section{Article history:}

Received 28 November 2013

Received in revised form 10 July 2014

Accepted 8 August 2014

\section{Keywords:}

Zebra mussel

Illicit drugs

Pharmaceuticals

Wastewater treatment

Bio-filtration

\begin{abstract}
A B S T R A C T
This study shows the evaluation of the possible use of the freshwater bivalve Dreissena polymorpha for the removal of some recalcitrant contaminants, namely many pharmaceuticals and drugs of abuse that are not sufficiently removed from civil wastewaters. This mollusk has an enormous filtering capability and is highly resistant to natural and anthropogenic stresses and to a significant bioaccumulation of lipophilic contaminants. All these characteristics may be particularly useful for the removal of compounds not easily eliminated by conventional wastewater treatment processes. To verify this hypothesis an experimental study was conducted at the pilot scale using a pilot plant installed in the largest wastewater treatment plant of Milan (Milano-Nosedo, Italy). First, we presented results obtained in several preliminary tests in order to evaluate the capability of zebra mussel specimens to survive in different wastewater mixtures, its filtering capacity and the possible influence of bio- and photo-degradation in the abatement of the molecules of interest. Finally, data obtained in the final tests demonstrated a capacity of this filter-feeder to reduce the concentrations of several pharmaceuticals and drugs of abuse higher than that obtained by the simple natural sedimentation, suggesting a possible implementation of the bio-filtration process in wastewater management.
\end{abstract}

(ㄷ) 2014 Elsevier B.V. All rights reserved.

\section{Introduction}

Today, the main challenge in the wastewater treatment of Western countries is the abatement of several environmental pollutants recalcitrant to removal, such as pharmaceuticals and personal care products (PPCPs), drugs of abuse and related metabolites. These compounds have been detected in sewage flows, surface and groundwater with levels generally ranging from traces to pbb values (Fatta-Kassinos et al., 2011). Despite it is known that these chemicals are to be associated with adverse effects in aquatic organisms at environmental relevant concentrations, it is now well accepted that conventional WWTPs are not designed to quantitatively remove micropollutants, because they are basically designed for the elimination of macropollutants (suspended solids, organic matter and nutrients). Thus, in the last decade, intense efforts have been made to improve the performances of WWTPs in respect

\footnotetext{
* Corresponding author. Tel.: +39 02 50314714; fax: +390250314713.

E-mail address: andrea.binelli@unimi.it (A. Binelli).
}

to micropollutants' removal by introducing new steps designed to remove such contaminants more efficiently (Batt et al., 2007; Clara et al., 2005a; Nakada et al., 2007). Thus, a plethora of several different new and pioneering methods have been developed and tested as final wastewater treatment to remove these pollutants, such as activated carbon adsorption (Yu et al., 2008), ozonation and advanced oxidation processes (Kim et al., 2008), membrane filtration (Snyder et al., 2007), reverse osmosis (Lee et al., 2012; Dolar et al., 2012) and bio-filtration (Reungoat et al., 2011). Unfortunately, each of them possesses several drawbacks and/or most of them are able to eliminate only specific contaminants. In fact, the current consensus on treatment in the research community is that no single technology can completely remove pharmaceuticals because of their very particular physical-chemical characteristics and that integration of removal technology may prove essential to handling of today's mixtures of compounds in wastewater (FattaKassinos et al., 2011). Moreover, their efficiency of removal is significantly affected by several factors: the physicochemical properties of pharmaceuticals, the treatment processes employed, the age of the activated sludge, the hydraulic retention time (HRT) and 
environmental parameters such as temperature and light intensity (Clara et al., 2005b; Andreozzi et al., 2003).

In this context, we tried for the first time worldwide a natural, not expensive and energy-free treatment for the abatement of some recalcitrant environmental pollutants from wastewaters exploiting the physiological characteristic of the freshwater bivalve zebra mussel (Dreissena polymorpha), which is well known for its huge filtering capacity. This filter feeder can filter a wide range of suspended particles of greater than $0.7 \mu \mathrm{m}$ from the water (Sprung and Rose, 1988), whose a percentage is assimilated (typically in the range of $15-40 \mu \mathrm{m}$; Ten Winkel and Davids, 1982) and the rest deposited to the benthic zone as faeces and pseudofaeces. Furthermore, zebra mussel has an enormous filtering capacity, ranging from 5 to $400 \mathrm{~mL} /$ bivalve/h (Ackerman, 1999; Baldwin et al., 2002) and the capability to reach a high population density, with more than 700,000 specimens $/ \mathrm{m}^{2}$ (Pathy, 1994). Its possible use in the wastewater treatments is also promoted by the great resistance to physical and chemical changes (e.g. temperature, $\mathrm{pH}$, hardness and salinity) and the ability to attach itself to hard substrates by the byssus. McLaughlan and Aldridge (2013) consider the freshwater filter feeders as "keystone organisms" or "ecosystem engineers" because they are characterized by a system that processes large volumes of water in order to trap and concentrate food from their surrounding. On the other hand, there are several evidences in the use of zebra mussel for environmental management as biofilter. Piesik (1983) examined almost thirty years ago the possible application of $D$. polymorpha in eutrophication control in a canal of Poland, concluding that these mussels succeeded in removing dissolved nutrients from the water. Richter (1986) gave preliminary results of a study in Lake Tjeukemeer (The Netherlands), which suggested zebra mussels could be effective tool for reducing algal density in Dutch lakes. Antsulevich (1994) proposed the construction of artificial reefs in the Neva Bay (Finland), which could be periodically removed and cleaned from uncrusting zebra mussels to improve the water quality. More recently, Elliott et al. (2008) tested the influence of different ecological factors, such as the density of the mollusks, the current speed and the amount of food, on the zebra mussel filtration capacity. These authors also suggested that zebra mussels could be used as an on-site industrial bio-filter for water treatment. Finally, Schernewski et al., 2012 considered the opportunities of using zebra mussel cultivation in the Szczecin Lagoon (Germany) in order to improve water quality. Although these evidences based on the capability of zebra mussel to be exploited in the environmental management, no data are available until now on the possible use of this filter feeder as complementary treatment in WWTPs. Thus, this study is a novelty in the wastewater management overview and could represent a possible starting point to take advantage on the natural characteristics of an aquatic organism that can be enforced in the prevailing engineering and chemical approaches. Our idea started from the consideration that many environmental chemicals are bound to suspended particulate matter (SPM) in different ways, depending not only on lipophilic properties, such as persistent organic pollutants (POPs), but also on specific other characteristics (cation exchange, complexation and hydrogen bonding), typical of some relatively polar or ionic chemical classes, such as pharmaceuticals and drugs of abuse (Lahti and Oikari, 2011; Baker and Kasprzyk-Hordern, 2011; Petrie et al., 2013; Darwano et al., 2014). Thus, we hypothesize that the very high filtration rate due to hundreds of thousands of zebra mussel specimens can decrease the concentration of several pollutants in wastewater by the increase of SPM deposition on the bottom of the plant. Moreover, the high filtration rate allows a fast intake of environmental pollutants in the mussel soft tissues, increasing their elimination from the wastewater. To verify this hypothesis, we carried out this research at the pilot scale at the largest WWTP of Milan
(Milano-Nosedo; Northern Italy) by the construction of a pilotplant that was implemented with other facilities during the entire study. In detail, we investigated the possible use of zebra mussel to decrease the concentrations of 13 pharmaceuticals (atenolol, carbamazepine, ciprofloxacin, clarithromycin, dehydroerythromycin, diclofenac, furosemide, ibuprofen, hydrochlorothiazide, ketoprofen, naproxen, ofloxacin, paracetamol) and 4 drugs of abuse (cocaine, benzoylecgonine, methamphetamines and methadone) still present in the outflow of the largest WWTP of Milan. Moreover, we showed also the results obtained in the needful preliminary tests carried out to verify the capacity of this mussel to live in different wastewater mixtures, the better conditions to maintain higher the filtration rate and data from tests conducted to evaluate the percentage of decrease of the chemical oxygen demand (COD), chosen as starting marker of the filtration capability of the zebra mussel specimens.

\section{Materials and methods}

\subsection{The pilot-plant}

Fig. 1 shows the pilot-plant and other equipment used for this project. In detail, the pilot-plant was a stainless steel tank with a volume of $1000 \mathrm{~L}(l=154 \mathrm{~cm}, h=102 \mathrm{~cm}, w=80.5 \mathrm{~cm})$ with 20 removable Plexiglas ${ }^{\circledR}$ panels (size of $70 \times 40 \mathrm{~cm}$; Fig. 2) to which the zebra mussel specimens attached themselves. The particular arrangement of panels forced the wastewater into a zigzag pathway to increase its residence time (Fig. 2). More than 2000 zebra mussel specimens were attached to each panel, for a total of approximately 40,000 individuals in the pilot-plant. The tank had a hopper bottom with five outflow valves to allow the collection and elimination of the sediments, faeces and pseudo-faeces (Fig. 1). A submerged pump collected the treated effluent directly from the canal between the sedimentation tanks and the sand filters of the WWTP. This position also guaranteed the lack of the possible accidental release of $D$. polymorpha specimens into the WWTP outflow because the sand filters and the following disinfection process (by peracetic acid) should stop and kill any leaked organism. Moreover, we added several plastic grids with a narrow mesh to all valves and outputs from the pilot-plant to prevent any mussel outflow. In the canal from which the effluent was pumped to the pilot-plant, the temperature ranged between 14 and $24^{\circ} \mathrm{C}$, the optimal survival temperature for zebra mussels (McMahon, 1996). We also added a 200 L re-circulation tank (Fig. 1) to feed the plant by re-circulation to investigate various hydraulic retention times $(30,60,90,120,15$, $180,210,240 \mathrm{~min})$. The re-circulation pump allowed a maximum waste flow of $3500 \mathrm{~L} / \mathrm{h}$. Finally, two "attachment tanks", in which the zebra mussels can attach themselves to panels by the byssus, completed the entire facility, in addition to a "nursery" (Fig. 1) in which the panels with the attached mussels can be stored before their placement into the pilot-plant. The pilot-plant and other facilities were completely cleaned cyclically by tap water and before each test to guarantee the best conditions and the elimination of the possible "memory effect" from the previous assay.

The mussels were collected by scuba divers at different times from Lake Maggiore and Lake Lugano, located at the ItalySwitzerland border. We gently detached the mussels from the submerged substrates (rocks, branches, anthropic wastes) and rapidly transferred them to the WWTP of Milano-Nosedo by refrigerated bags to decrease any stress factors.

First, we conducted the following preliminary tests: (1) evaluation of the time and method required for the mussels' adhesion to the panels; (2) adaptation of the individuals to the fed effluent; (3) control of the possible concentration decrease of pharmaceuticals 


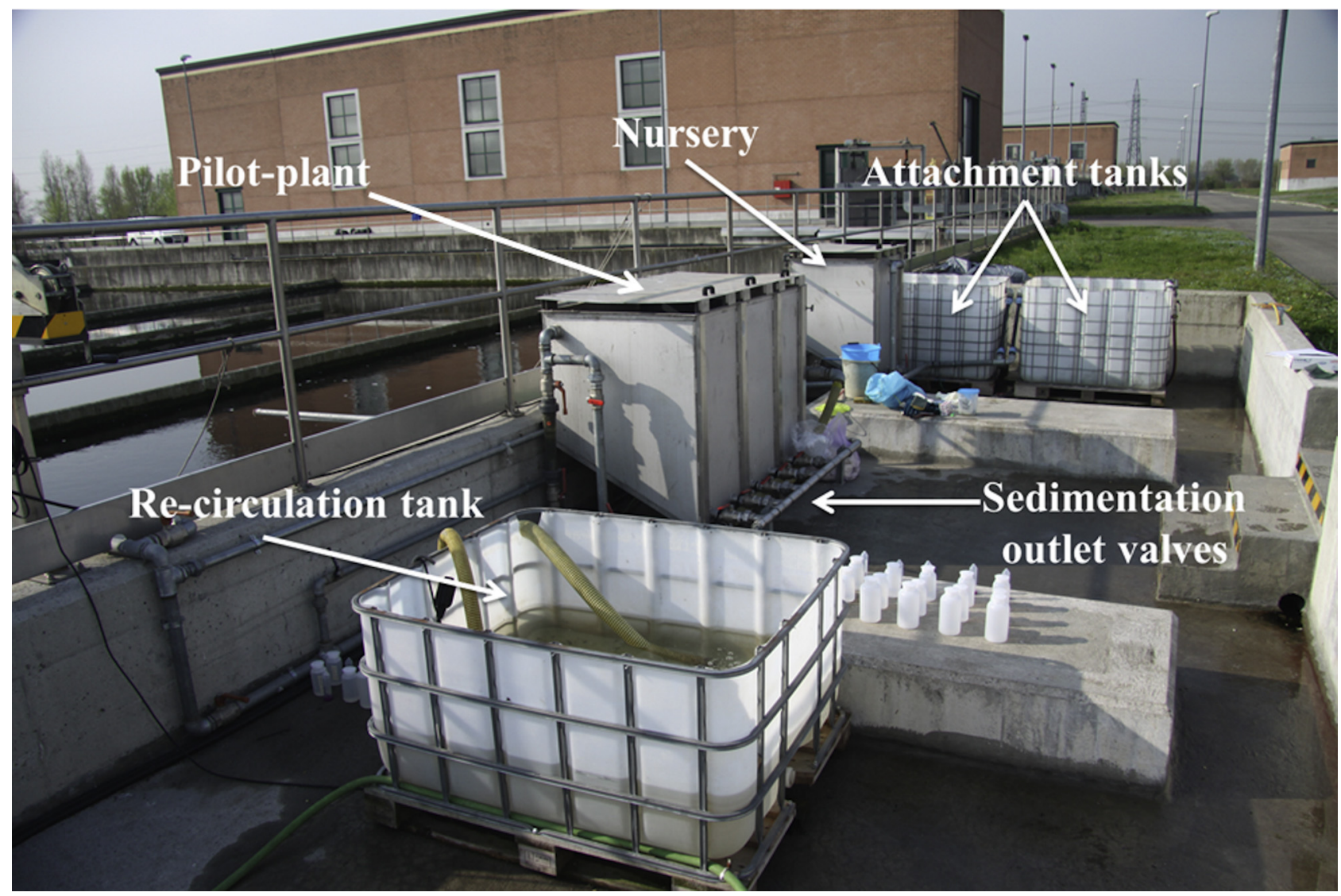

Fig. 1. Structure of the pilot-plant and all the facilities.

and drugs of abuse due to photo- and bio-degradation and (4) evaluation of the removal efficiency of COD by the zebra mussels. Only after the positive check of these conditions, we moved to the final assays to evaluate the possible abatement of some pharmaceuticals and illicit drugs in the final WWTP outflow.

\subsection{Analytical characterization of the fed effluent}

As mentioned above, the bio-filtration was first fed on the secondary effluents (after biological treatment and secondary settling). As the effluent had very low COD, suspended solid and fecal coliform concentrations, tests were performed on different inflow/outflow mixtures to evaluate the performance of the biofiltration for different pollutant concentrations and provide the mussels with the needed feed. The mean starting chemical characteristics and the Escherichia coli counts in the used mixtures are reported in Table 1.

\subsection{Adaptation of mussels to the effluent}

Once adherent to the Plexiglas ${ }^{\circledR}$ panels, the $D$. polymorpha specimens were laid inside the pilot-plant and placed in contact with the wastewater, which was pumped into the tank directly from the post-sedimentation canal. The idea of using D. polymorpha in the tertiary treatments assumed that the mussels could live in the effluents, which have physico-chemical properties different from those of the freshwater. Thus, some tests were conducted to control the good health conditions of the animals. We fed the mussels twice a week with Spirulina spp. to provide the needed food as the effluent had very low organic matter content $\left(B D_{5} \approx 3 \mathrm{mg} / \mathrm{L}\right)$. We monitored the mussel health status by measuring the total content of proteins and lipids in their soft tissues. To evaluate these physiological parameters, many bivalves (five mussels for proteins and thirty for lipids' determination) were gently cut off from the panels at different times by the excision of the byssus and frozen at $-20^{\circ} \mathrm{C}$ until the analyses. Unfortunately, the mussel soft tissue obtained at each time point was sufficient to perform the measurement of proteins in triplicate (about $1.2 \mathrm{~g}$ fresh weight for each pool) but not for the lipid determination (about $7 \mathrm{~g}$ fresh weight), which could only be performed once. To quantify the protein content, we removed the shell and byssus and subsequently homogenized the soft tissues in a solution of phosphate buffer $\left(100 \mathrm{mM} \mathrm{KH}_{2} \mathrm{PO}_{4} / \mathrm{K}_{2} \mathrm{HPO}_{4}\right.$, $\left.\mathrm{pH} 7.4\right)$ and $0.1 \%$ Triton. The samples were placed at $4{ }^{\circ} \mathrm{C}$ in a refrigerated centrifuge at $12,000 \mathrm{rpm}$ for $15 \mathrm{~min}$. The proteins were quantified by the BCA Protein Assay Kit (Thermo Fisher Scientific, Rockford, USA) using bovine serum albumin (BSA) as the standard. For the quantification of lipids, the mussel soft tissues were lyophilized and extracted using $100 \mathrm{~mL}$ of an acetone $/ n$-hexane $(1: 1 \mathrm{v} / \mathrm{v})$ mixture in a Soxhlet apparatus (FALC Instruments, Lurano, Italy). The samples were subsequently reduced in volume with a rotary evaporator, transferred to $5 \mathrm{~mL}$ tubes and gently evaporated under a nitrogen stream. The lipid content was then measured by gravimetric determination.

\subsection{Evaluation of the zebra mussel removal efficiency}

Because some environmental pollutants are bound to the particulate matter, we chose the measurement of COD as preliminary markers of the possible chemical removal. Thus, to evaluate the efficiency of $D$. polymorpha in removing the selected compounds, we compared the COD changes obtained after the tests with and without mussels in the pilot-plant. For these tests, performed under 


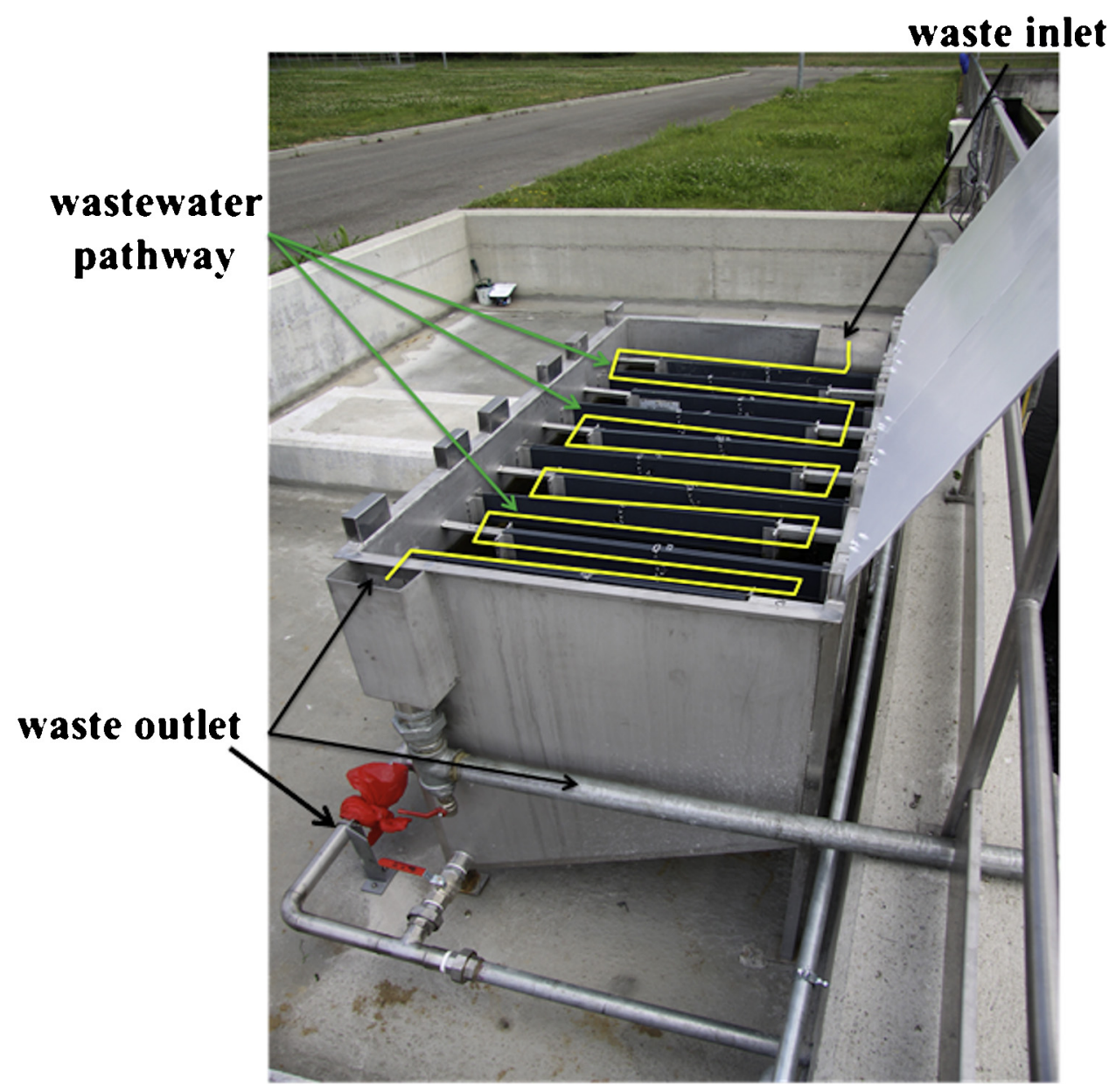

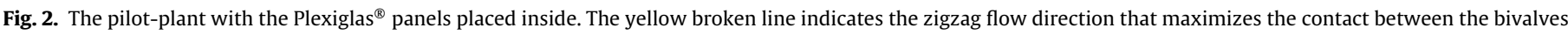
and wastewater.

the re-circulation condition, we added approximately 40,000 animals to the pilot-plant, which was self-powered solely by the outflow waste pumped from the post-sedimentation canal (waste flux $=3500 \mathrm{~L} / \mathrm{h}$ ), allowing a residence time of $15 \mathrm{~min}$ in the pilotplant. The time of complete re-circulation was $18 \mathrm{~min}$ as we added other $200 \mathrm{~L}$ of waste to the re-circulation tank (Fig. 1). This experimental design enabled a longer contact of the waste with the mussels because the waste re-circulates approximately 14 times in $4 \mathrm{~h}$. Because the COD value in the outflow is normally very low (approximately $10-15 \mathrm{mg} / \mathrm{L}$ ), we first added $32 \mathrm{~g}$ of Spirulina spp. to the pilot-plant to increase the starting COD to approximately $50 \mathrm{mg} / \mathrm{L}$, after mixing the algal suspension with waste in the recirculation tank for $20 \mathrm{~min}$ to reach a good homogenization. After these preliminary tests, we conducted other assays with different wastewaters obtained by mixing the inflow and the outflow of the WWTP in different proportions. In detail, we performed four tests in triplicate using the following waste ratios: (1) the outflow effluent from the WWTP, (2) the inflow waste of the WWTP, (3) $50 \%$ inflow and $50 \%$ outflow and (4) $25 \%$ inflow and $75 \%$ outflow. Before the addition of the inflow waste to the treated effluent, we preliminarily filtered the former with a bag filter (mesh $=1 \mathrm{~mm}$ ) to eliminate the gross particulate matter. In each test, we measured the COD every $30 \mathrm{~min}$ for $4 \mathrm{~h}$ to obtain the removal slope for both assays, with and without mussels. In detail, we collected $50 \mathrm{~mL}$ of the mixture from the pilot-plant every $30 \mathrm{~min}$ for a total of $4 \mathrm{~h}$ to follow the two COD decrease slopes. The samples were placed in plastic bottles, immediately acidified with $1 \mathrm{~mL} \mathrm{H}_{2} \mathrm{SO}_{4}$ and transported in refrigerated bags to the laboratory, where the samples

Table 1

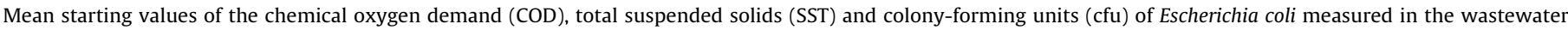
mixtures used in the preliminary tests.

\begin{tabular}{|c|c|c|c|c|}
\hline & Wastewater mixture & COD mg/L & TSS mg/L & E. coli $\mathrm{cfu} / 100 \mathrm{~mL}$ \\
\hline \multirow[t]{4}{*}{ Without mussel } & $100 \%$ OUT & $15 \pm 2$ & $7 \pm 3$ & $6 \times 10^{3} \pm 2 \times 10^{3}$ \\
\hline & $25 \%$ IN & $38 \pm 15$ & $20 \pm 6$ & $2 \times 10^{5} \pm 8 \times 10^{4}$ \\
\hline & $50 \%$ IN & $59 \pm 8$ & $35 \pm 11$ & $4 \times 10^{5} \pm 9 \times 10^{4}$ \\
\hline & $100 \%$ IN & $132 \pm 43$ & $101 \pm 24$ & $2 \times 10^{6} \pm 6 \times 10^{5}$ \\
\hline \multirow[t]{4}{*}{ With mussel } & $100 \%$ OUT & $12 \pm 1$ & $5 \pm 1$ & $6 \times 10^{3} \pm 4 \times 10^{3}$ \\
\hline & $25 \%$ IN & $37 \pm 10$ & $32 \pm 18$ & $2 \times 10^{5} \pm 6 \times 10^{4}$ \\
\hline & $50 \%$ IN & $52 \pm 10$ & $26 \pm 10$ & $5 \times 10^{5} \pm 1 \times 10^{5}$ \\
\hline & $100 \%$ IN & $94 \pm 23$ & $97 \pm 30$ & $2 \times 10^{6} \pm 5 \times 10^{5}$ \\
\hline
\end{tabular}


were analyzed within $24 \mathrm{~h}$. For the COD measurement, we used the Hach Lange kit (LCK414 COD; 5-60 mg/L) coupled with the Hach Lange LT 200 digester and the Hach Lange DR 3900 spectrophotometer.

\subsection{Evaluation of the abatement of pharmaceuticals and illicit drugs}

These tests were carried out in re-circulation conditions with a constant flow rate of $3500 \mathrm{~L} / \mathrm{h}$. We covered the re-circulation tank with a dark plastic bag to protect the waste from light and the pilotplant was already equipped with three plastic hard tops. First, we performed four assays without mussels in the pilot-plant for $6 \mathrm{~h}$ to verify the possible role played by photo- and bio-degradation of these pollutants: (1) the treated effluent that flows from the sedimentation tank of the WWTP; (2) the inflow waste of the WWTP; (3) $50 \%$ of inflow and $50 \%$ of treated effluent and (4) $25 \%$ of inflow and $75 \%$ of treated effluent. Before the addition of the inflow waste to the treated effluent, we preliminarily filtered the former with a bag filter ( mesh $=1 \mathrm{~mm}$ ) to eliminate the gross particulate matter. Then, to evaluate the abatement of pharmaceuticals and drugs of abuse contained in the wastewater, we performed four assays with the same types of wastes described above to investigate the possible role played by the different quantity of suspended particulate matter in these processes. Since the residence time of the wastewater in the WWTP of Milano-Nosedo is $24 \mathrm{~h}$, these assays were conducted initially for $4 \mathrm{~h}$ in order to maintain a temporal condition compatible with the possible future engineering of the process. Additionally, we decided the extension of the exposure time until $24 \mathrm{~h}$ for the last two mixtures (50\% inflow $/ 50 \%$ outflow; $25 \%$ inflow $/ 75 \%$ outflow), which showed the better performances, in order to investigate the possible relationship between filtration rate and time of contact with the chemicals present in the wastewaters. Then, we tested the eventual decrease in the chemical concentration in the pilot-plant without mussels (controls) for all the wastewater mixtures. In these tests, performed in November 2012, we equipped the re-circulation tank with four submerged heaters to maintain the temperature of the wastewater at $15^{\circ} \mathrm{C}$ also during the night. From the analytical point of view, the water samples (2 L) were first stored at $-20^{\circ} \mathrm{C}$ until analysis and successively filtered on a mixed cellulose membrane filter $0.45 \mu \mathrm{m}$ (Whatman, Kent, U.K.). Samples ( $50 \mathrm{~mL}$ for raw wastewater and $100 \mathrm{~mL}$ for treated wastewater) were solid-phase extracted by a mixed reversed-phase cation exchange cartridge (Oasis-MCX). Before extraction, the $\mathrm{pH}$ was adjusted to 2 with $37 \% \mathrm{HCl}$, and the samples were spiked with the labeled deuterated compounds used as internal standards: atenolol d7, carbamazepine d10, ciprofloxacin d8 and ibuprofen d3 (Sigma Aldrich, Steinheim, Germany) as well as cocaine d3, benzoylecgonine d3, methamphetamine d9 and methadone d3 (Cerilliant Corporation, Round Rock, TX, USA). The cartridges were conditioned before use by washing with $6 \mathrm{~mL}$ methanol, $3 \mathrm{~mL}$ MilliQ water and $3 \mathrm{~mL}$ water acidified to $\mathrm{pH} 2$. Samples were then passed through the cartridges at a flow rate of $5-10 \mathrm{~mL} / \mathrm{min}$. Cartridges were vacuum-dried for $10 \mathrm{~min}$ and eluted with $2 \mathrm{~mL}$ of methanol and $2 \mathrm{~mL}$ of a $2 \%$ ammonia solution in methanol. The eluates were dried under a nitrogen stream. The dried samples were redissolved in $200 \mu \mathrm{L}$ of MilliQ water, centrifuged, transferred into glass vials and analyzed by HPLC-MS/MS (high-pressure liquid chromatography-tandem mass spectrometry) following previously validated analytical methods (Castiglioni et al., 2005, 2011; Zuccato et al., 2008). In the last assays, we measured also two other pharmaceuticals: paracetamol and ibuprofen, not preliminary considered in the photo- and bio-degradation tests.

\subsection{Statistical analyses}

Data normality and homoscedasticity were verified using the Kolmogorov-Smirnov and Levene's tests, respectively. We performed a statistical comparison (SPSS 21 IBM software package) between tests carried out with and without mussels in the pilotplant. For all these cases, we conducted the comparison using the one-way analysis of variance (ANOVA; $p<0.05 ; p<0.01$ ).

\section{Results and discussion}

As no data are available about the possible use of $D$. polymorpha for wastewater treatment purposes, conducting some preliminary tests was necessary to investigate some operative problems and to organize in the most appropriate way the project plan to reach the correct data interpretation in the final assays. Thus, we showed first data from these preliminary tests, and then results obtained with pharmaceuticals and illicit drugs.

\subsection{Adhesion of the mussels to panels and adaptation of individuals to the effluent}

One of the first crucial problems faced in our project was how to attach thousands of mussels to each panel without damaging them or decreasing their filtration capability. To solve this problem, we decided to exploit the natural behaviour of $D$. polymorpha to produce the byssus. Thus, the collected specimens were simply placed on plastic panels stored horizontally in the attachment tanks (Fig. 3) filled with tap water, waiting the time required to establish a sufficient physical bond by the byssus. We evaluated the best conditions that guaranteed the minor stress to bivalves by taking advantage of this natural adhesion. We conducted several tests that highlighted the need to observe few simple precautions: (1) the transport of mussels from the sampling site to the pilotplant should be performed as fast as possible and (2) the time of adhesion must be sufficient to increase the resistance of the byssus, which will be able to support the weight of the animal then positioned vertically in the pilot-plant. Indeed, although we observed that 6-7 days were generally sufficient to guarantee an adequate adhesion to the substrate, we preferred to wait at least two weeks before the final placement in the pilot-plant. Furthermore, in the final tests in which these two simple conditions have been maintained, we noticed a very low mussel mortality rate during the entire test time.

To evaluate the health status of the $D$. polymorpha specimens exposed to the outflow effluent of WWTP, we measured the total content of lipids and proteins in their soft tissues over the next three months after their sampling. Fig. 4A shows only a slightly decreasing trend in the percentage of lipids, reaching a final percentage of approximately $10 \%$ of the dry weight, which is absolutely comparable with that found in several surveys performed using this biological model in the Italian sub-alpine great lakes (Binelli and Provini, 2003; Binelli et al., 2006, 2008). Furthermore, no significant $(p>0.05)$ increase was noticed in the protein content (Fig. 4B). The obtained data confirmed the acclimatization and adaptation of these mollusks to the physico-chemical characteristics of the final waste, showing a remarkable resistance of the bivalve.

\subsection{Evaluation of the COD removal efficiency}

Because the preferential food of this filter-feeder is algae and suspended particulate matter, to which some pollutants are bound, the measurement of COD can indirectly highlight the potential removal efficiency of $D$. polymorpha with respect to these 


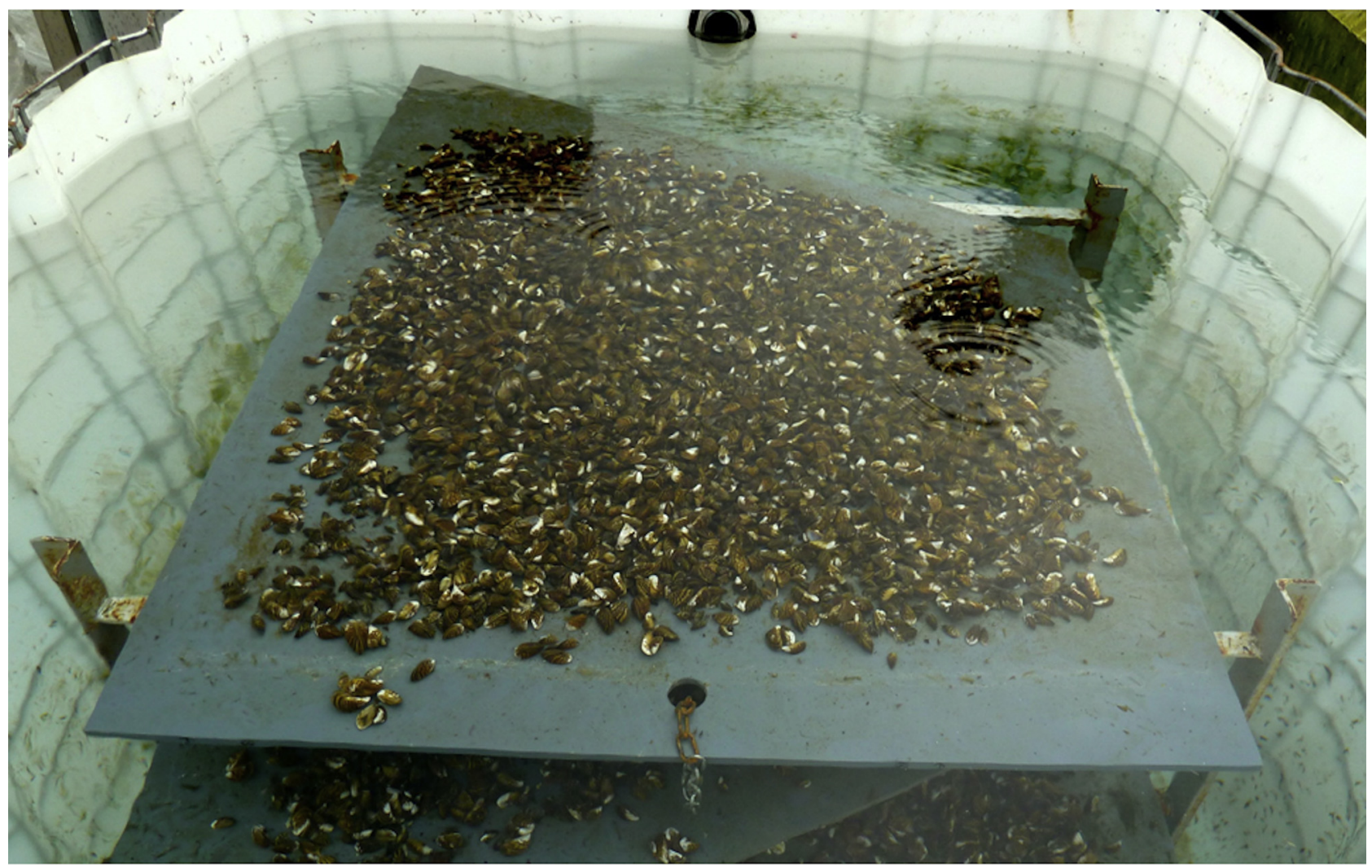

Fig. 3. Plexiglas ${ }^{\circledR}$ panels with bivalves placed horizontally inside the attachment tanks.
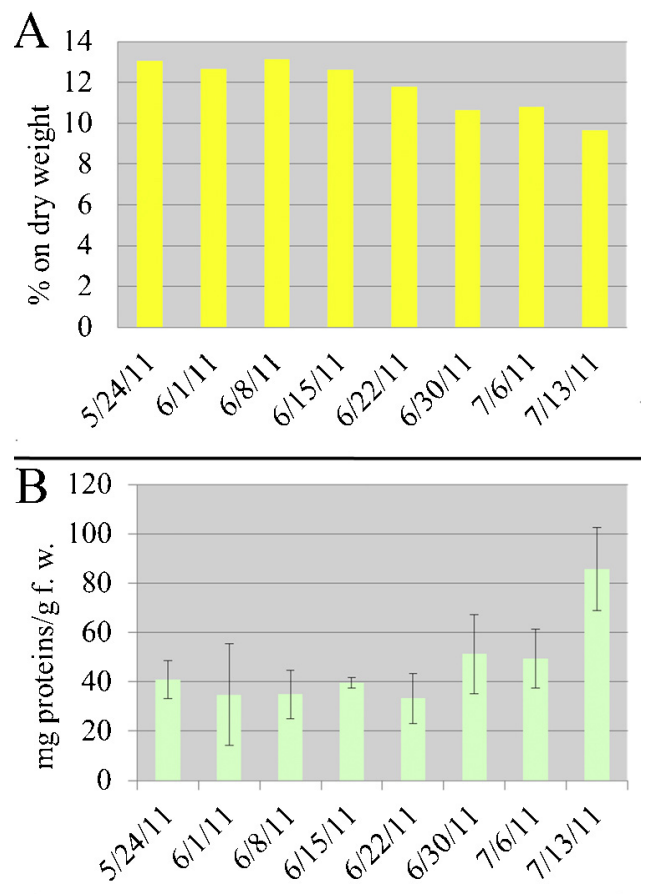

Fig. 4. Lipid (\%; (A)) and protein ( $\mathrm{mg} / \mathrm{mL} \pm$ standard deviation; (B)) content measured in the soft tissues of $D$. polymorpha exposed to the WWTP effluent for two months after the sampling.

recalcitrant chemicals. Thus, preliminary tests were conducted considering the decrease of COD due to the mussel filtration compared with the control tests performed without bivalves in the pilot-plant.
Fig. 5 clearly shows the higher and significant COD removal rate (one-way ANOVA, $F=809.9 ; p<0.001$ ) observed in the experiments conducted with the zebra mussel specimens in the pilot-plant compared with the controls without mussels. After a linear starting phase of $60 \mathrm{~min}$, in which the two slopes were completely overlapped, the removal rate due to the zebra mussel filtration continued to be linear $\left(R^{2}=0.95\right)$, with an increase of $42 \%$ after $4 \mathrm{~h}$. In contrast, the COD slope obtained without mussels tended to an asymptote $\left(R^{2}=0.90\right)$. The percentage of COD abatement without the mussels was only $19 \%$, which was produced by the natural algal and particulate matter sedimentation. Therefore, it can be concluded that $D$. polymorpha is able to break down by bio-filtration approximately $20 \%$ of the COD in the filtered wastewater supplemented with Spirulina spp. after $4 \mathrm{~h}$ and potentially the same percentage of the pollutants bound to the suspended particulate matter.

Once the feasibility of the $D$. polymorpha to filter its food has been established, the final preliminary step was the evaluation of the COD removal in wastewaters with different physical-chemical properties, in which the organic/inorganic matter ratio is very different (Fig. 6). The choice to investigate the potential bio-filtration potency with four different wastewaters' mixtures (the outflow effluent from the WWTP; the inflow waste of the WWTP; $50 \%$ inflow and $50 \%$ outflow and $25 \%$ inflow and $75 \%$ outflow) allowed the investigation of both the presence of toxic substances in the wastes that decrease the pumping rate of mussels and/or increase their mortality and the possible change in the removal efficiency due to the different quantities of suspended particulate matter. Because the starting COD is different for each test due to the high intrinsic variability of the wastewater, we should normalize the data to compare the results obtained with the simple sedimentation and with the filtration effect by the mussels. Fig. 6 shows the comparison between the specific removal rates obtained with 


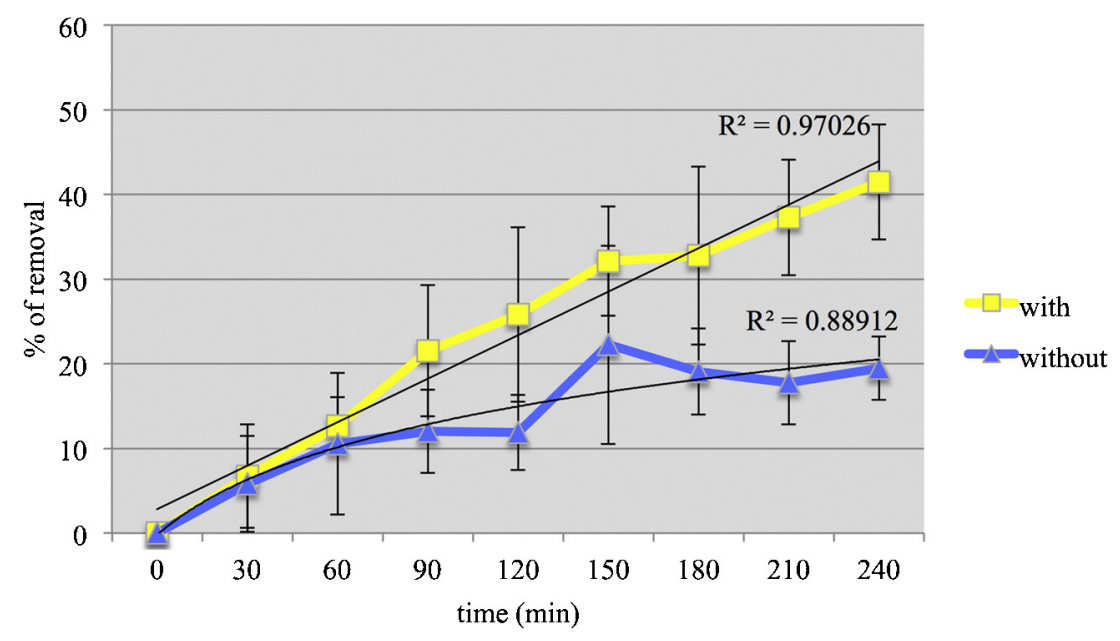

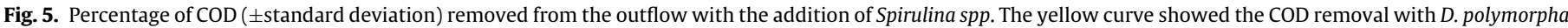
specimens in the pilot-plant, whereas the blue curve showed the COD decrease in the control test (without zebra mussels).

and without mussels in the pilot-plant for four hydraulic retention times (HRTs; 60, 120, 180 and $240 \mathrm{~min}$ ) related to the COD $(\mathrm{mg} / \mathrm{L})$ measured at these HRTs. No differences were noticed in the outflow effluent tests, as expected, because the starting COD value (mean $=12 \mathrm{mg} / \mathrm{L}$ ) was too low to highlight any variation. Moreover, as expected, the specific removal rates were increased with the increasing COD in the wastewater and are higher for the early times both in the controls and in the presence of $D$. polymorpha. We can highlight that the higher COD removal trend was always obtained by the additional filtration effect of the bivalves compared with the removal rates produced only by the natural sedimentation, although there were no significant differences $(p>0.05)$ between the two treatments. As the COD concentration measured at the single HRT for the test pairs (with and without zebra mussels) is different, we can use the equations describing the trend lines to compare the effect of only the sedimentation with that obtained by the filtration activity of $D$. polymorpha. For example, the mussels were able to remove from the $50 \%$ inflow $/ 50 \%$ outflow a mean of $40.8 \mathrm{~g}$ of $\mathrm{COD} / \mathrm{h}$ at $40.7 \mathrm{mg}$ of COD/L (Fig. 6, $60 \mathrm{~min}$ ), whereas the simple sedimentation can remove only $23.0 \mathrm{~g}$ of $\mathrm{COD} / \mathrm{h}$ at the same COD concentration, based on data from the equation describing the COD removal rate. This finding corresponds to a removal due to the mussel filtration of $44 \%$ higher than that obtained solely with the natural sedimentation. Thus, the zebra mussel specimens could be able to increase, in the same manner, the removal of the chemicals associated with the particulate matter from the wastewater.

Finally, because these preliminary results showed that the better performance was obtained mainly for the wastewater mixture of $50 \%$ inflow $/ 50 \%$ outflow (Fig. 6), the zebra mussels' filtration basically appears to be more effective with higher values of

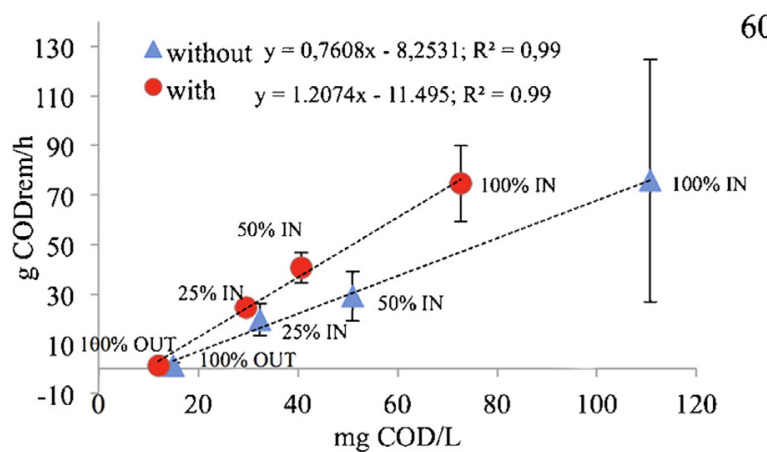

$60 \mathrm{~min}$
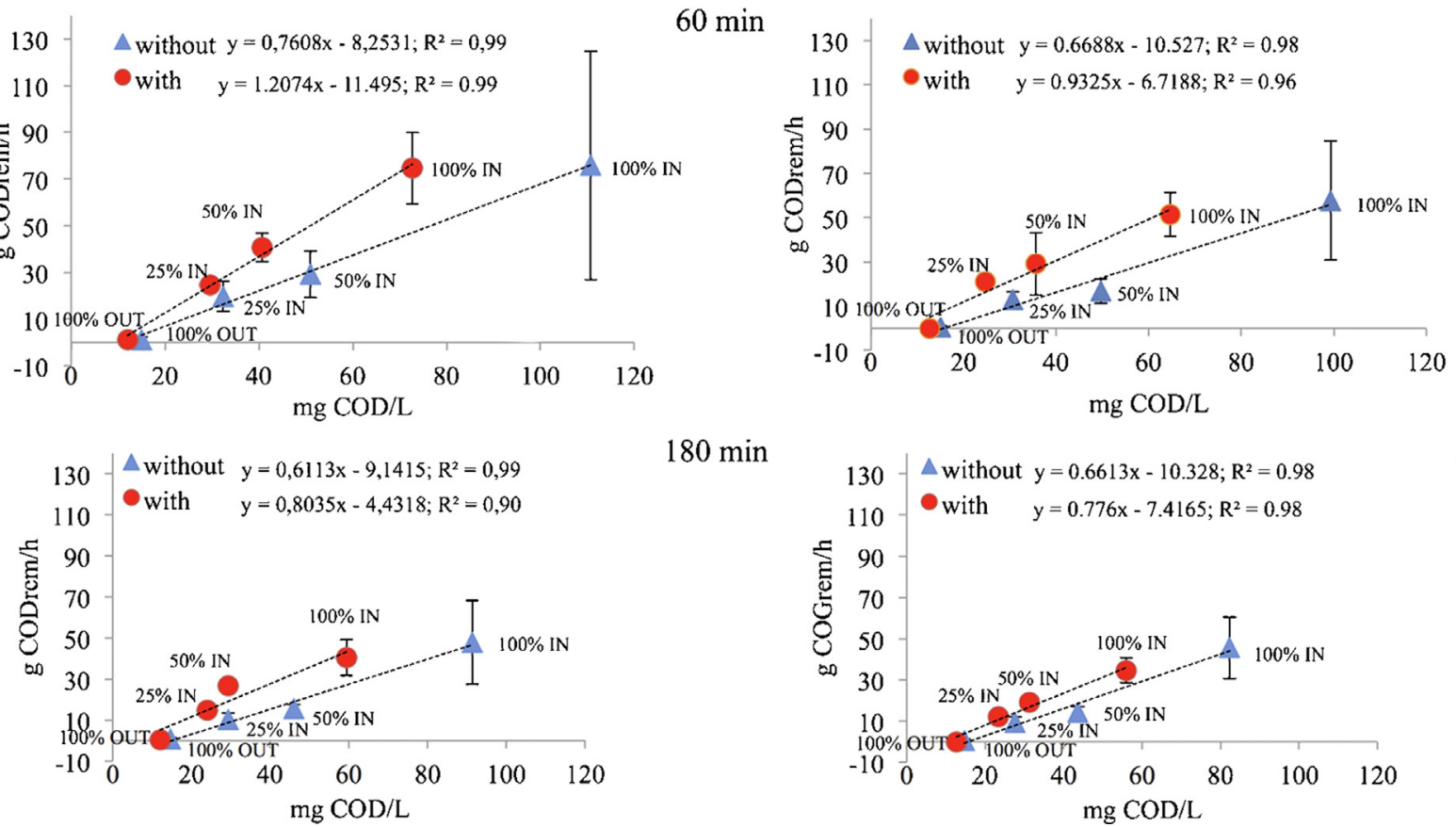

$180 \mathrm{~min}$

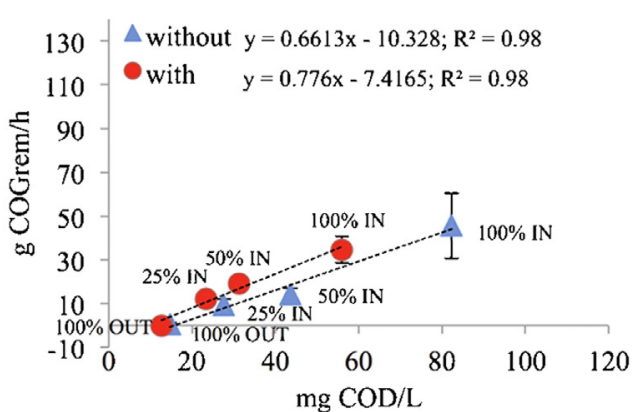

$240 \mathrm{~min}$

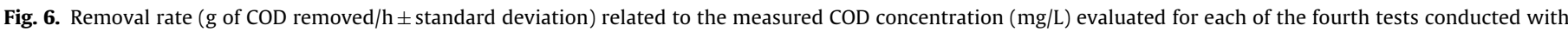

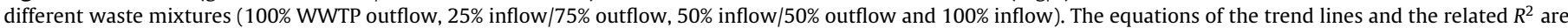
also shown. 
initial COD (30-40 mg/L) than those usually found in the very clean outflow from the WWTP of Milan-Nosedo (10-20 mg/L). However, the European Union Municipal Wastewater Directive fixed $125 \mathrm{mg}$ $\mathrm{COD} / \mathrm{L}$ as the limit for WWTP outflow into the freshwater, and several outflows generally present a COD value of $60-70 \mathrm{mg} / \mathrm{L}$, comparable with the apparent best level for filtration by the $D$. polymorpha specimens.

\subsection{Measurements of the abatement of pharmaceuticals and illicit drugs}

These environmental pollutants represent the new challenge in the field of wastewater treatments because some of the most widely used pharmaceutical classes, such as antibiotics and non steroidal anti-inflammatory drugs (NSAIDs), reach levels comparable with those of many POPs both in freshwaters, wastewaters and groundwater. The fate and transformation of pharmaceuticals depend on the basis of their special physical-chemical and biological characteristics, which are very complex and different from other industrial chemical compounds (Fatta-Kassinos et al., 2011). These characteristics include polymorphism, their continuous introduction into the environment after human metabolism, their chemically complex structure and the fact that they can be ionized and have multiple ionization sites spread throughout the molecule (Cunningham, 2008). Particular attention should be made to polymorphisms that arise when a molecule has the ability to crystallize in more than one form, giving to polymorphic forms with different physical, chemical, electrical and thermal properties. Thus, the polymorphs usually differ in bioavailability, solubility, dissolution rate, chemical and physical stability. Moreover, pharmaceuticals may be acid, basic or neutral and of variety of chemical forms, such small organic molecules, large polymers, carbohydrates and other compounds with complex chemistry (Fatta-Kassinos et al., 2011). These very different physical-chemical properties make very difficult the comprehension of their fate and behaviour especially in wastewaters, where the bacterial community can also transform the parent compound into a variety of degradation products. In fact, because of the great availability of glucose in biological systems, glucoronide formation is one of the most common mechanisms of pharmaceutical metabolism (Fatta-Kassinos et al., 2011). Therefore, the administered parent compound may be excreted unchanged, as a glucoronide or sulfate conjugate and as a complex mixture of many metabolites. There is evidence that glucoronides, which are the simplest and most common form of conjugated pharmaceuticals excreted by humans, are capable of being deconjugated to the parent compound during municipal sewage treatment (Kozak et al., 2001). For serotonin reuptake inhibitors, benzodiazepines, carbamazepine and macrolide antibiotics negative removal is often observed during conventional treatments. This is usually attributed to biotransformation of conjugates (Gros et al., 2010). Finally, the degree of ionization of pharmaceuticals at a particular $\mathrm{pH}$ will affect its bioavailability to organisms, its physical and chemical activity and its ultimate environmental fate. For example, an ionized molecule will generally have greater water solubility and will be less likely than its nonionized form to partition to lipid-like substances (Cunningham, 2008). All these particular characteristics make difficult both a correct qualitative and quantitative evaluation of these pollutants in wastewaters, and the achievement of a single abatement system able to decrease their levels before the following outflow in the environment.

Results obtained by our tests were in some cases extremely variable and sometimes contrasting, pointing out the difficulties in data treatment of this pollutants' class. This lack of homogeneity seems not due to photo- and biodegradation that can interfere on the quali-quantitative evaluation of these classes of chemicals in the aquatic environments (Konstantinou et al., 2010). In fact, Fig. 7 shows the concentrations of pharmaceuticals and drugs of abuse at the beginning (T0) of the assays and after $6 \mathrm{~h}$ (T6) of recirculation measured in the pilot-plant without zebra mussels and filled with 100\% WWTP outflow (Fig. 7A), 25-75\% (v/v inflow:outflow; Fig. 7B), 50-50\% (v/v inflow:outflow; Fig. 7C) and 100\% inflow (Fig. 7D), respectively. These data pointed out that the precaution taken in our tests (see Section 2.5) make irrelevant these environmental processes because of no significant variations $(p>0.05)$ of the chemicals' concentration were noticed at the end of these assays. Obviously a slight decrease due to natural sedimentation was present, since we obtained after $6 \mathrm{~h}$ of recirculation an average decrease of $12 \%, 11 \%$ and $9 \%$ for $50 \%$ inflow-50\% outflow, $25 \%$ inflow $/ 75 \%$ outflow and $100 \%$ outflow mixtures, respectively. By contrast, results obtained with the last test ( $100 \%$ inflow) were different because a mean increase of $9 \%$ in respect with the starting chemicals' concentrations was noticed. In fact, only carbamazepine $(-8.5 \%)$ and furosemide $(-10.8 \%)$ showed the expected decrease, while all the other compounds slightly raised its level in the wastewater. This can be due to the higher amount of particulate matter, especially formed by the finest materials that cannot be able to sediment rapidly.

Overall, results highlighted a great variability in the pharmaceutical abatement in the final tests conducted until $4 \mathrm{~h}$ not only with the mussels in the pilot plant, but also in the controls, and mainly for the two extreme wastewater mixtures (100\% inflow and $100 \%$ outflow). This is probably due to two opposite reasons: the final outflow of the WWTP contains very poor quantity of suspended matter, which can be filtered by mussels with the bounded chemicals, while the sewage from Milan (100\% inflow) probably had the contrary physical and chemical characteristics, with an excessive quantity of suspended particulate matter that block the gills with the consequent death of the mussels. Another hypothesis should be due to the possible presence of specific toxicants for $D$. polymorpha in the sewage. On the other hand, after this last test, carried out at the end of the entire campaign, we observed a great mortality of zebra mussel specimens and an increase of the byssus detachment from the panels, a clear stress symptom for this species.

The variability observed after only $4 \mathrm{~h}$ of exposure was probably due to the peculiar chemical and physical properties and the unexpected behaviours above-mentioned. Thus, we showed only data from the intermediate wastewaters' mixtures (25\% inflow $/ 75 \%$ outflow and $50 \%$ inflow/50\% outflow) carried out for $24 \mathrm{~h}$, which showed a more homogeneous behaviour. Fig. 8A (25\% inflow/75\% outflow) points out that the biofiltration due to the mussels is able to decrease the level of several pharmaceuticals and drugs of abuse better than the simple natural sedimentation (controls). In detail, paracetamol seems to be the chemical more prone to the abatement because the daily decrease due to the effect of the mussels' filtration is double than that found after the control tests (Fig. 8A). However, the greatest difference between the biofiltration effect and the natural sedimentation is not obtained for paracetamol, but for other pharmaceuticals: biofiltration determined an abatement of the $\beta$-blocker atenolol four times higher than controls, over than three times for the dehydro-erythromycin, the main metabolite of the antibiotic erythromycin, and eight times higher for the ibuprofen, one of the most used NSAIDs worldwide. The abatement noticed for carbamazepine and ofloxacin is more difficult to explain because controls showed pharmaceuticals levels slightly higher than the starting concentrations, even if the biofiltration effect determined a clear decrease of their final concentrations ( $52 \pm 11 \mu \mathrm{g} / 24 \mathrm{~h}$ and $141 \pm 48 \mu \mathrm{g} / 24 \mathrm{~h}$, respectively). The slight rise of levels observed for controls probably points out that these two molecules do not possess a great capability to 

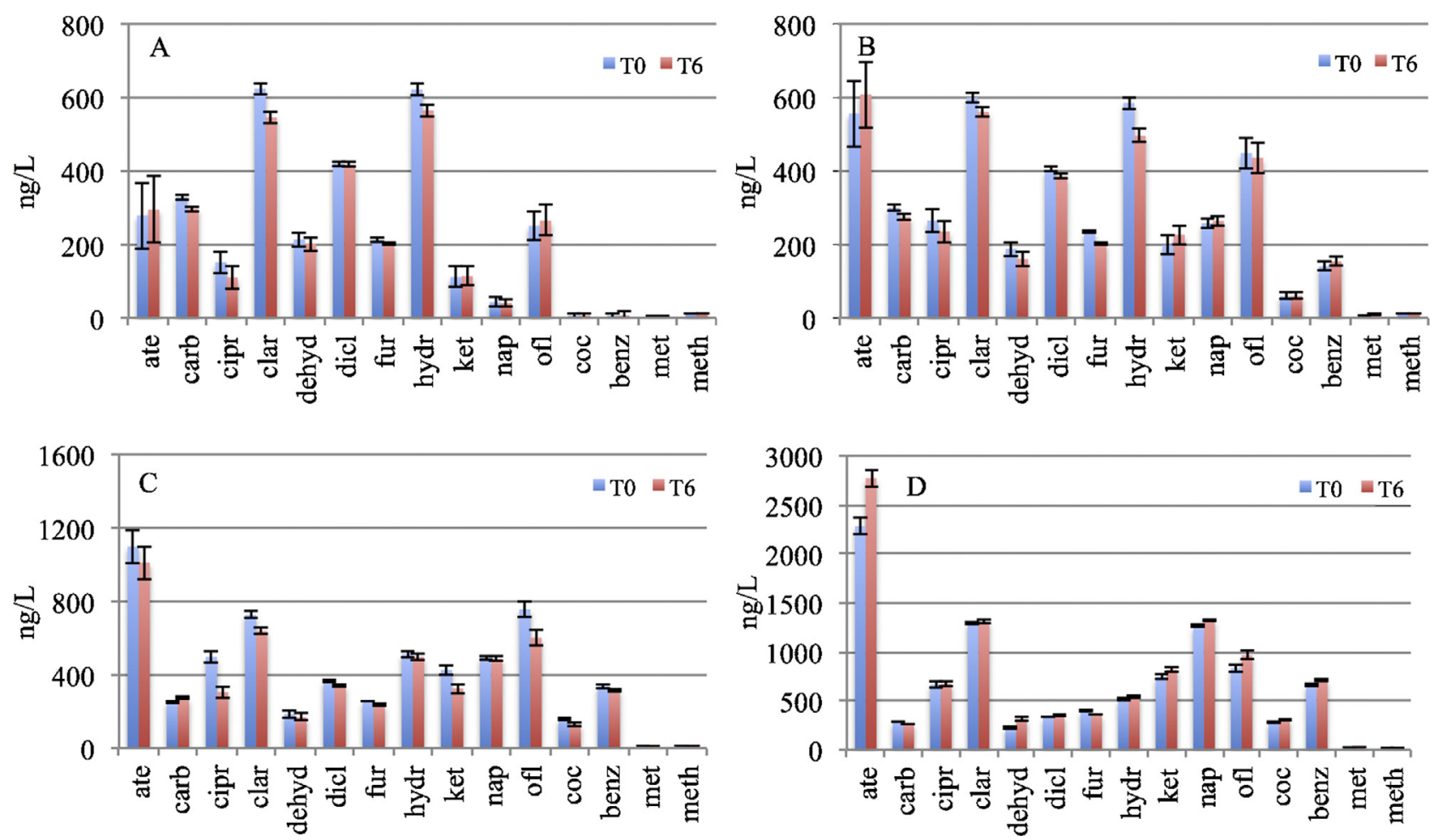

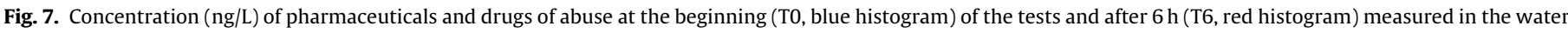

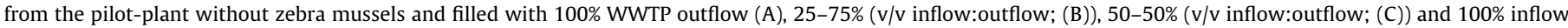
(D), respectively. Standard deviations from the marginal means were also shown.

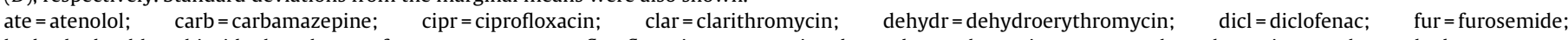
hydr = hydrochlorothiazide; ket = ketoprofen; nap = naproxen; ofl = ofloxacin; $\operatorname{coc}=$ cocaine; benz = benzoylecgonine; met = methamphetamine; meth = methadone .

sedimentation and the only process able to decrease their concentrations is just the biofiltration. The illicit drugs showed a more homogeneous trend with a final decrease more than double to controls for cocaine, over six times higher for its main metabolite (benzoylecgonine) and amphetamine, and about 1.5 times higher for methadone, even if the measured concentrations of the last two drugs were very low. On the contrary, the effect of the biofiltration seems to be irrelevant for other pharmaceuticals, namely diclofenac and naproxen. Finally, we must highlight the more controversial cases observed for four pharmaceuticals (ciprofloxacin, furosemide, hydrochlorothiazide, ketoprofen), in which the final concentrations were sharply higher than those measured at the start of the assays (Fig. 8A). Since these rises of levels are observed also in the test carried out with a second wastewater mixture (Fig. 8B), but not in the controls, this points out a clear role of zebra mussel. Due to the great variability in the behaviour of some pharmaceuticals and the very different chemical-physical characteristics, we can only suggest some hypotheses to explain this apparent contradiction. Ciprofloxacin, furosemide and hydrochlorothiazide are generally excreted in unconjugated form. Moreover, these molecules possess in their structures an acid and a basic group that determine two different dissociation constants at least. This can heavily interfere on the molecules' interaction with the suspended particulate matter in relation to $\mathrm{pH}$ changes. Although this parameter was not measured during the $24 \mathrm{~h}$ assays, there are predictable little $\mathrm{pH}$ variations due to mussels' metabolism, which can modify the ionic state of these pharmaceuticals. Thus, we can suppose that these compounds were mainly bound to suspended particulate matter at the start of the assays and less present in the aqueous phase. The possible change of their ionic states, due to $\mathrm{pH}$ variations made by zebra mussels' metabolism, should increase their affinity to the aqueous phase with a consequent partial or total detachment of the molecules from the particulate matter. Thus, this affinity modification contemporarily does not allow to mussels the decrease of pharmaceutical concentration in the wastewater, since they become not bioavailable with the suspended particulate matter, increasing at the same time their instrumental reconnaissance. However, this suggestion cannot be applied to ketoprofen because it does not possess any acid or basic groups and it is excreted as conjugated form (about 85\% of ketoprofen-glucuronide; Baselt, 2004). Thus, zebra mussel can be able to de-conjugate this chemical, using the glucoronide for its metabolism, increasing the concentration of ketoprofen in the wastewater by means the excretion. The great transformation of ketoprofen-glucuronide to the parent compound can be also promoted by the re-circulation conditions followed in these tests. In confirmation of the unexpected behaviour of some pharmaceuticals, depending both of their very particular physical-chemical characteristics and some environmental factors, such as $\mathrm{pH}$, temperature and the quantity of suspended particulate matter, we can highlight that the same four pharmaceutics involved in the concentration increase showed the same trend also in the test carried out with the second wastewater mixture (Fig. 8B). Surprisingly, other molecules (ibuprofen, naproxen, ofloxacin, paracetamol) showed the same behaviour only in the control assays, carried out without mussels in the pilot-plant. Since ibuprofen, naproxen and paracetamol were excreted in conjugated form, the bacterial community, greater than that present in the waste mixture above-described, could de-conjugate the metabolites, increasing their concentration in the waste. This means that the biofiltration should be more efficient for these pharmaceuticals because mussels' action was able to decrease them after $24 \mathrm{~h}$. 

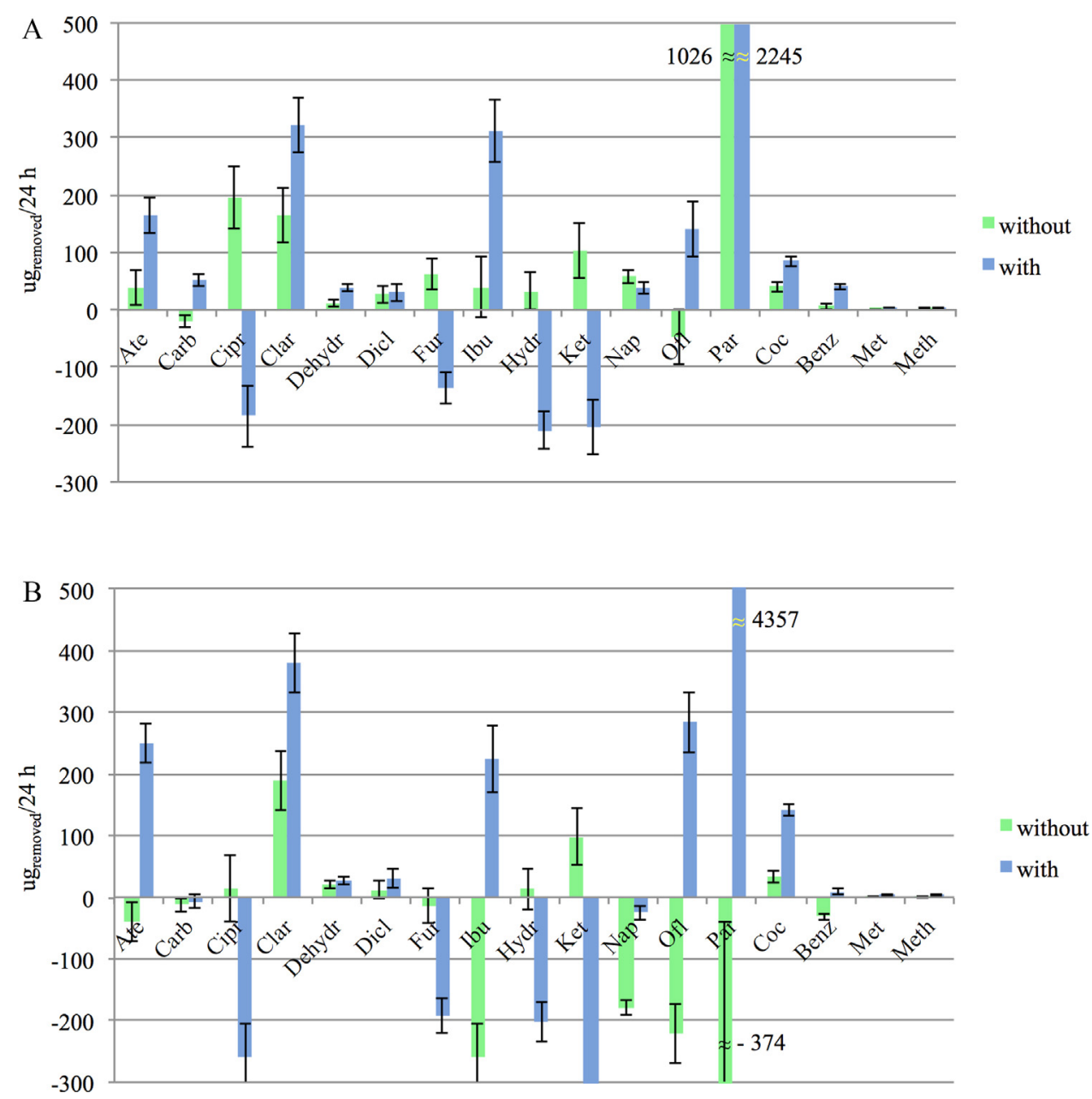

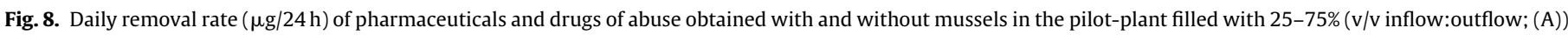
and $50-50 \%$ (v/v inflow:outflow; (B)). Standard deviations from the marginal means were also shown.

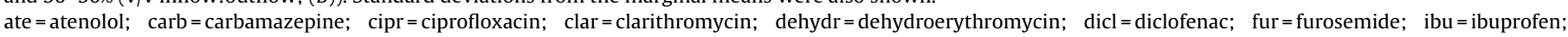

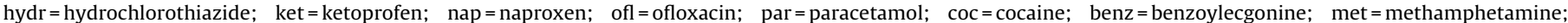
meth $=$ methadone.

On the contrary, this explanation is not valid for ofloxacin that is excreted in non-conjugated form. The only current possible suggestion of its particular behaviour can be due to the property of similar fluoroquinolones (ciprofloxacin and norfloxacin), which are mainly bound to sludge (Golet et al., 2003) and consequently to suspended particulate matter. Thus, a change of particulate content in the tested wastewater mixture (from $25 \%$ inflow/75\% outflow to $50 \%$ inflow/50\% outflow) can modify the bioavailability of ofloxacin to bacteria.

Notwithstanding the evident difficulties in data interpretation, we can point out as the biofiltration effect seems remarkable for many compounds: paracetamol confirmed surely the best abatement performance previously noticed with more than $4000 \mu \mathrm{g}$ eliminated from the wastewater in $24 \mathrm{~h}$. Other significant abatements were registered for clarithromycin (380 $\left.\pm 48 \mu \mathrm{g}_{\text {removed }} / 24 \mathrm{~h}\right), \quad$ ofloxacin $\left(284 \pm 48 \mu \mathrm{g}_{\text {removed }} / 24 \mathrm{~h}\right)$, atenolol $\left(250 \pm 31 \mu \mathrm{g}_{\text {removed }} / 24 \mathrm{~h}\right)$ and ibuprofen (225 \pm $\left.54 \mu \mathrm{g}_{\text {removed }} / 24 \mathrm{~h}\right)$, as well as the cocaine $\left(142 \pm 9 \mu \mathrm{g}_{\text {removed }} /\right.$ $24 \mathrm{~h})$.

The mechanism of the clear abatement of several pharmaceuticals and drugs of abuse observed after $24 \mathrm{~h}$ due to $D$. polymorpha biofiltration can be only presumed since, for instance, only very recently a method to measure their levels in mussels is available (Klosterhaus et al., 2013). We hypothesized that zebra mussels can catch the SPM from wastewater and put them through faeces and pseudofaeces into the bottom of the pilot plant together with the adsorbed chemicals. Since we previously filtered $(0.45 \mu \mathrm{m})$ the samples, we can suggest that these pollutants are bound to the finest SPM, as occur for some POPs. On the other hand, we preliminary tested both the filtered fraction and the part of SPM remained on the filter, obtaining a negligible concentration of the studied chemicals in this last fraction (data not shown). Moreover, also Darwano et al. (2014) assert that the portion of suspended particulates in a WWTP, that would be more recalcitrant to sedimentation, would be smaller and lighter and thus remain in the effluent without other treatments. Furthermore, such smaller SPM would tend to have a greater specific surface area to which these chemicals can be bound at higher concentration. Other possible hypotheses can be due to the bioaccumulation and/or metabolism of certain chemicals. Klosterhaus et al. (2013) found several pharmaceuticals and drugs of abuse in the soft tissues of the benthic ribbed horsemussel (Geukensia demissa) from San Francisco Bay (CA, USA). Interestingly, since the calculated bioaccumulation factor (BAF) was much higher than that the model-predicted BCF (bioconcentration factor), the Authors explained this apparent discrepancy through the partitioning or binding of these particular chemicals to a non-lipid compartment (e.g. protein binding or active transport processes rather than passive diffusion). Finally, zebra mussel can be able 
to biotransform the parent compounds into different metabolites, which cannot be longer revealed by instrumental determinations. Therefore, when it is establish that $D$. polymorpha could be useful for the abatement of pharmaceuticals and drugs of abuse, it will be necessary other studies in order to investigate the mechanism to which it is able to do it.

\section{Conclusions and future prospects}

Although the reported results are only preliminary, they highlight for the first time a natural and inexpensive method to polish biologically treated effluents from some recalcitrant pollutants. The idea to try this new type of treatment based on the natural behaviour of a species, considered in several countries to be an alien species, appears to be encouraging even if many other tests must be conducted to verify this possibility before the engineering of the entire process. During the project, we improved our knowledge about many technical and logistic problems, not possible to foresee before the starting of the assays. Since the better performances were obtained with certain characteristics, namely a greater time of exposure and the right quantity of suspended particulate matter, we concluded that the next step to the possible grand-scale use of the biofiltration technique shall be tested in small reservoirs, such as the phytodepuration and lagooning systems, where the residence time are generally a few days long. Moreover, one of the crucial problems to solve in the next future will be the need to collect many zebra mussels, since each of our tests was carried out with about 40,000 specimens in the pilot plant. This number is doomed to increase proportionally to the volume of the reservoir, forcing a fast method to collect hundreds of thousand zebra mussels in the natural ecosystems. In this context, there are just encouraging studies about the possible cultivation of this species by very simple methods in a cost-effective way (McLaughlan and Aldridge, 2013). Another problem to engage for a possible future engineering of this process is the management of mussels, which can bioaccumulate not only these particular chemicals, but also other environmental pollutants from wastewaters (e.g. POPs and heavy metals). Thus, mussels must be regularly substituted with clean animals both to maintain a higher concentration gradient between biota and wastewater and contemporarily eliminate the polluted mollusks. On the other hand, also sludge from the WWTPs and the vegetable biomass in the phytodepuration plants must be treated as dangerous wastes, but the advantage made by the use of $D$. polymorpha is surely be due to the lower weight of waste to dispose.

Finally, we must avoid the escape from the plant of adult specimens and larvae of this alien species. Thus, the placement of the pilot plant before the sand filters and the peracetic treatment resulted essential and must be followed with similar expedients in a possible engineering of the system. In fact, we would not advocate the introduction of this invasive species for water quality management, but rather propose that we consider embracing their positive attributes in controlled systems, positioned in the areas where they are already established. In fact, the recourse for these purposes to zebra mussel, considered an alien species in many countries, seems to be encouraging only if many precautions are made to avoid not only any mussel outflow, but also the escape of the veliger larvae that were produced up to 1 million per individual per year (McIsaac et al., 1992). Obviously, in a conservation context, the ideal situation would be to use native mussels, such as freshwater unionids, but unfortunately they are in decline worldwide since several years (Bogan, 1993) and its reproduction depends on parasitic larval stage in fish that can represent a sure disadvantage in a possible future industrialization of the biofiltration process.

\section{Acknowledgements}

We thank the WWTP of Milano-Nosedo for the willingness in collaborating in the study and for providing the facilities and areas, which have been essential to carry out the research. We also mean to mention the Aqualab Foundation to support this study and the Cariplo Foundation to co-fund this project and which financed two post-doc grants.

\section{References}

Ackerman, J.D., 1999. Effect of velocity on the filter feeding of dreissenid mussels (Dreissena polymorpha and Dreissena bugensis): implications for trophic dynamics. Can. J. Fish. Aquat. Sci. 56, 1551-1561.

Andreozzi, R., Marotta, R., Paxeus, N., 2003. Pharmaceuticals in STP effluents and their solar photodegradation in aquatic environment. Chemosphere 50 , 1319-1330.

Antsulevich, A.E., 1994. Artificial reefs project for improvement of water quality and environmental enhancement of Neva Bay (St. Petersburg County region). Bull. Mar. Sci. 55, 1189-1202.

Baker, D.R., Kasprzyk-Hordern, B., 2011. Multi-residue determination of the sorption of illicit drugs and pharmaceuticals to wastewater suspended particulate matter using pressurised liquid extraction, solid phase extraction and liquid chromatography coupled with tandem mass spectrometry. J. Chromatogr. A 1218, 7901-7913.

Baldwin, B.S., Mayer, M.S., Dayton, J., Pau, N., Mendilla, J., Sullivan, M., Moore, A. Ma, A., Mills, E.L., 2002. Comparative growth and feeding in zebra and quagga mussels (Dreissena polymorpha and Dreissena bugensis): implications for North American lakes. Can. J. Fish. Aquat. Sci. 59, 680-694.

Baselt, R.C., 2004. Disposition of Toxic Drugs and Chemicals in Man, seventh ed. Biomedical Publications, Foster City, CA.

Batt, A.L., Kim, S., Aga, D.S., 2007. Comparison of the occurrence of antibiotics in four full-scale wastewater treatment plants with varying designs and operations. Chemosphere 68, 428-435.

Binelli, A., Provini, A., 2003. DDT is still a problem in developed countries: the heavy pollution of Lake Maggiore. Chemosphere 52 (4), 717-723.

Binelli, A., Guzzella, L., Roscioli, C., 2008. Levels and congener profiles of polybrominated diphenyl ethers (PBDEs) in Zebra mussels ( $D$. polymorpha) from Lake Maggiore (Italy). Environ. Pollut. 153, 610-617.

Binelli, A., Ricciardi, F., Riva, C., Provini, A., 2006. Integrated use of biomarkers and bioaccumulation data in Zebra mussel (D. polymorpha) for the site-specific quality assessment. Biomarkers 11 (5), 428-438.

Bogan, A.E., 1993. Freshwater bivalve extinctions (Mollusca: Unionoida): a search for causes. Am. Zool. 33 (6), 599-609.

Castiglioni, S., Bagnati, R., Calamari, D., Fanelli, R., Zuccato, E., 2005. A multiresidue analytical method using solid-phase extraction and HPLC-MS-MS to measure pharmaceuticals of different therapeutic classes in urban wastewaters. J. Chromatogr. A 1092, 206-215

Castiglioni, S., Bagnati, R., Melis, M., Panawennage, D., Chiarelli, P., Fanelli, R., Zuccato, E., 2011. Identification of cocaine and its metabolites in urban wastewate and comparison with the human excretion profile in urine. Water Res. 45 5141-5150.

Clara, M., Strenn, B., Gans, O., Martinez, E., Kreuzinger, N., Kroiss, H., 2005a. Removal of selected pharmaceuticals, fragrances and endocrine disrupting compounds in a membrane bioreactor and conventional wastewater treatment plants. Water Res. 39, 4797-4807.

Clara, M., Kreuzinger, N., Strenn, B., Gans, O., Kroiss, H., 2005b. The solids retention time-a suitable design parameter to evaluate the capacity of wastewater treatment plants to remove micropollutants. Water Res. 39, 97-106.

Cunningham, V.L., 2008. Special characteristics of pharmaceuticals related to environmental fate. In: Kummerer (Ed.), Pharmaceuticals in the Environment. Springer-Verlag, Berlin, pp. 23-34.

Darwano, H., Duy, S., Sauvé, S.Vo., 2014. A new protocol for the analysis of pharmaceuticals, pesticides, and hormones in sediments and suspended particulate matter from rivers and municipal wastewaters. Arch. Environ. Contam. Toxicol. 66, 582-593.

Dolar, D., Gros, M., Rodriguez-Mozaz, S., Moreno, J., Comas, J., Rodriguez-Roda, I. Barceló, D., 2012. Removal of emerging contaminants from municipal wastewater with an integrated membrane system, MBR-RO. J. Hazard. Mater. 239-240 64-69.

Elliott, P., Aldridge, D.C., Moggridge, G.D., 2008. Zebra mussel filtration and its potential uses in industrial water treatment. Water Res. 42, 1664-1674.

Fatta-Kassinos, D., Merci, S., Nikolaou, A., 2011. Pharmaceuticals residues in environmental waters and wastewater: current state of knowledge and future research. Anal. Bioanal. Chem. 399, 251-265.

Golet, E.M., Xifra, I., Siegrist, H., Alder, A.C., Giger, W., 2003. Environmental exposure assessment of fluoroquinolone antibacterial agents from sewage to soil. Environ. Sci. Technol. 37 (15), 3243-3259.

Gros, M., Petrović, M., Ginebreda, A., Barceló, D., 2010. Removal of pharmaceuticals during wastewater treatment and environmental risk assessment using hazard indexes. Environ. Int. 36, 15-26. 
Kim, I.H., Tanaka, H., Iwasaki, T., Takubo, T., Morioka, T., Kato, Y., 2008. Classification of the degradability of 30 pharmaceuticals in water with ozone, UV and $\mathrm{H}_{2} \mathrm{O}_{2}$. Water Sci. Technol. 57 (2), 195-210.

Klosterhaus, S.L., Grace, R., Hamilton, M.C., Yee, D., 2013. Method validation and reconnaissance of pharmaceuticals, personal care products, and alkylphenols in surface waters, sediments, and mussels in an urban estuary. Environ. Int. 54, 92-99.

Konstantinou, I.K., Lambropoulou, D.A., Albanis, T.A., 2010. Photochemical transformation of pharmaceuticals in the aquatic environment: reaction pathways and intermediates. In: Fatta-Kassinos, D., Bester, K., Kummerer, K. (Eds.), Xenobiotics in the Urban Water Cycle. Springer, Environmental Pollution, Dordrecht (Netherlands), pp. 179-194.

Kozak, R.G., D’Haese, I., Verstraete, W., 2001. In: Kummerer (Ed.), Pharmaceuticals in the Environment. Springer-Verlag, Berlin.

Lahti, M., Oikari, A., 2011. Pharmaceuticals in settleable particulate material in urban and non-urban waters. Chemosphere 85, 826-831.

Lee, C.O., Howe, K.J., Thomson, B.M., 2012. Ozone and biofiltration as an alternative to reverse osmosis for removing PPCPs and micropollutants from treated wastewater. Water Res. 46, 1005-1014.

McIsaac, H.J., Sprules, R.G., Johannsson, O.E., Leach, J.H., 1992. Filtering impacts of larval and sessile zebra mussel (Dreissena polymorpha) in western Lake Erie. Oecologia 92 (1), 30-39.

McLaughlan, C., Aldridge, D.C., 2013. Cultivation of zebra mussels (Dreissena polymorpha) within their invaded range to improve water quality in reservoir. Water Res. 47, 4357-4369.

McMahon, R.F., 1996. The physiological ecology of the zebra mussel, Dreissena polymorpha in North America and Europe. Am. Zool. 36, 339-343.

Nakada, N., Shinohara, H., Murata, A., Kiri, K., Managaki, S., Sato, N., Takada, H., 2007 Removal of selected pharmaceuticals and personal care products (PPCPs) and endocrine-disrupting chemicals (EDCs) during sand filtration and ozonation at a municipal sewage treatment plant. Water Res. 41, 4373-4382.
Pathy, D.A., 1994. The Life History and Demography of Zebra Mussel, Dreissena polymorpha, Populations in Lake St. Clair, Lake Erie, and Lake Ontario. University of Guelph, Guelph, ON, M. Sc. Thesis; Volume 33/02 of Masters Abstracts, pp. 489.

Petrie, B., McAdam, E.J., Scrimshaw, M.D., Lester, J.N., Cartmell, E., 2013. Fate of drugs during wastewater treatment. Trends Anal. Chem. 49, 145-159.

Piesik, Z., 1983. Biology of Dreissena polymorpha (Pall.) settling on stylon nets and the role of this mollusc in eliminating the seston and the nutrients from the watercourse. Polskie Archiwum Hydrobiologii 30, 353-371.

Reungoat, J., Escher, B.I., Macova, M., Keller, J., 2011. Biofiltration of wastewater treatment plant effluent: effective removal of pharmaceuticals and personal care products and reduction of toxicity. Water Res. 45, 2751-2762.

Richter, A.F., 1986. Biomanipulation and its feasibility for water quality management in shallow eutrophic water bodies in the Netherlands. Hydrobiol. Bull. 20 (1-2), $165-172$.

Schernewski, G., Stybel, N., Neumann, T., 2012. Zebra mussel farming in the Szczenin (Oder) Lagoon: water-quality objectives and cost-effectiveness. Ecol. Soc. 17 (2), 4.

Snyder, S.A., Adham, S., Redding, A.M., Cannon, F.S., De Carolis, J., Oppenheimer, J., Wert, E.C., Yoon, Y., 2007. Role of membranes and activated carbon in the removal of endocrine disruptors and pharmaceuticals. Desalination 202 (1-3), $156-161$.

Sprung, M., Rose, U., 1988. Influence of food size and food quantity on the feeding of the mussel Dreissena polymorpha. Oecologia 77 (4), 526-532.

Ten Winkel, E.H., Davids, C., 1982. Food selection by Dreissena polymorpha Pallas (Mollusca: Bivalvia). Freshwater Biol. 12, 553-558.

Yu, Z.R., Peldszus, S., Huck, P.M., 2008. Adsorption characteristics of selected pharmaceuticals and an endocrine disrupting compound-naproxen, carbamazepine and nonylphenol on activated carbon. Water Res. 42 (12), 2873-2882.

Zuccato, E. Castiglioni, S., Bagnati, R., Chiabrando, C., Grassi, P., Fanelli, R. 2008. Illicit drugs, a novel group of environmental contaminants. Water Res. 42, 961-968. 